\title{
Wind Power Cooperative Scheduling Strategy Considering the Life Cycle Carbon Emissions of EV
}

\author{
Fengkun Yang ${ }^{1,2}$ and Liangliang Chen ${ }^{1,2}$ \\ ${ }^{1}$ NARI Group Corporation/State grid electric power research institute, NO.19, Chengxin Avenue, Jiangning Nanjing, Jiangsu \\ China \\ ${ }^{2}$ NARI Nanjing Control System Co. Ltd, NO.19, Chengxin Avenue, Jiangning Nanjing, Jiangsu China
}

\begin{abstract}
In order to improve the low-carbon and economic benefits of electric vehicles (EV), this paper proposes a cooperative dispatch model of electric vehicles and wind power. The objectives of the model include the lowest carbon emissions, the lowest cost of thermal power and the lowest equivalent load variance. In addition, $\mathrm{EV}$ carbon emission reduction benefits are taken into account including the carbon emissions of the whole life cycle and the carbon trading mechanism. Finally, multiobjective particle swarm optimization (MPSO) algorithm is applied to achieve the optimal charging strategy of EV and comparison analysis is carried out with fuel vehicles and the scenarios of disordered charging of electric vehicles. The results verifies the superiority of the model in economic and environmental efficiency in a practical case.
\end{abstract}

Keywords-electric vehicles; carbon trading; wind power; lowcarbon economic dispatch

\section{INTRODUCTION}

With the development of the economy and increasing attention of people to environmental issues, the status of clean energy continues to increase.in recent years, technology of China's clean energy has developed very rapidly. As one of the important clean energy sources, wind power has great advantages in economy and environment, and research on wind power has also been pushed forward. However, the wind power output has obvious volatility and anti-peaking characteristics. The time-domain fluctuations of large-scale grid-connected wind power generation in wind power generation will result in insufficient peak adjustment of the power grid and affect the stability of the power system. During the low period of the load, the lack of system capacity for peak adjustment will also cause problems of wind curtailment.

In addition, due to its good environmental benefits, electric vehicles have got strong support and development from the country in recent years. With the development of electric vehicle technology, especially the excellent performance of the battery and the excellent charging performance of the motor and its control system, the development of electric vehicles has been significantly accelerated. When driving electric vehicles, the carbon emission depends on the primary energy structure, and China's energy structure is still mainly in the form of thermal power. Therefore, the carbon emission per unit mileage of electric vehicles may even be higher than traditional ones in some cases. As a result, the emission reduction capability of electric vehicles has been greatly limited. In addition, due to the influence of vehicle owners' travel habits, after a large number of electric vehicles enter the grid and load peak hours, they will also increase the peak-tovalley difference and system pressure. The disordered charging behavior of a large number of electric vehicles will affect the safety and reliability of the system.

With regard to solving the above problems, many studies have been conducted at home and abroad at this stage. Document [1] proposes a coordinated scheduling strategy for electric vehicles and wind power generation, adjusting peakto-valley differences through the dispatch of electric vehicles, and absorbing more wind power. The document [2] analyzes the role and role that electric vehicle charging can play in lowcarbon power systems. Document [3] analyzes the strategy of carbon emission reduction achieved by electric vehicles instead of traditional automobiles. Document [4] took carbon emission as the minimum scheduling objective and analyzed the carbon emission reduction benefits under the reasonable dispatch of electric vehicle charging. Document [5] considers the demand response, takes the user cost into account and proposes a charging strategy model for the electric vehicle with the smallest load variance and the lowest thermal power and user costs. Document [6] aims to optimize the scheduling of electric vehicle charging with the goal of maximizing load variance, minimizing $\mathrm{SO}_{2}$ emissions, and minimizing the cost of thermal power. Document [7-11] considers the interests of the user side and proposes a system of time-of-use electricity price, taking the smoothing fluctuations of load into account and reducing the load peak-to-valley difference. The Document [12] proposes two charging modes, namely, searching for the lowest load period and reverse-reversal, based on time-of-use price. Document [13] proposed a rolling optimization control strategy based on time-of-use electricity price, and compared with out-of-order charging, the result can effectively reduce user costs and achieve the purpose of peak load reduction. Document [14] studied carbon reduction strategies for virtual power plants. Document [15] proposes a two-tier scheduling model that considers the interests of users at the upper level, considers user satisfaction at the lower level, and minimizes the deviation from the upper model. Document [16] uses the concept of a virtual power plant to schedule electric vehicles, thermal power plants, and clean energy as a whole, to schedule the charging of electric vehicles, aiming at maximum returns and adding carbon trading concepts to them. It can be seen that the coordinated dispatching of electric vehicles and wind power can solve the above problems well. 
However, the current research basically stays in consideration of peak-to-valley difference, power generation cost, or user cost, while ignoring the benefits of carbon reduction, or the sole condition for considering carbon emissions alone.

This paper aims at the lowest carbon emission and lowest system cost, and joins the carbon trading mechanism, fully analyzes the carbon emission reduction level of the scheduling strategy, giving economic value of carbon emission reduction on the base of consideration of reducing the variance of equivalence load. In addition, the paper analyzes the carbon emissions per unit of electric vehicles under different wind power installed capacity to compare with the fuel vehicles.

\section{CARBON EMISSION LEVELS OF ELECTRIC VEHICLE LIFE CYCLE}

In order to calculate the carbon emission level of an electric vehicle that participates in dispatching and compares it with a fuel-powered vehicle and a disordered charging one, the carbon emissions generated during the life cycle of an electric vehicle cannot be ignored. Therefore, the life cycle approach is used for calculating the carbon emission from the life cycle of electric vehicles. The life cycle approach examines the energy demand, raw material used and activities that may cause pollution emissions in each unit of the product life cycle in detail. It divides the life cycle of electric vehicles into three processes, production, use, and waste recovery[17].Production stage can be divided into traditional automobile manufacturing parts and lithium battery manufacturing parts. In the use phase, the carbon emissions of electric vehicles mainly depend on the type of primary energy and its impact on the environment. When it is reported as worthless, the impact of scrapping and recycling automotive materials on the environment is mainly analyzed. Comparing the life cycle of an electric vehicle with the life cycle of a fuel vehicle, it can be found that the main difference lies in the manufacture of lithium batteries and the carbon emissions during driving. In this article, in order to compare the carbon emissions of fuel vehicles and electric vehicles, this two parts of the life cycle are mainly analyzed.

During the lithium battery manufacturing stage, the main energy consumed is electrical energy. The manufacturing process is divided into two parts: raw material preparation and battery assembly. In the raw material preparation process, the power consumption is mainly calculated based on the weighted average power consumption of each raw material manufacturing, and the weight is the corresponding content in the battery. Due to the complexity of materials, we mainly take large energy consumption and large raw materials used in lithium-ion batteries which are made domestically into consideration. The formula is as follows:

$$
E_{c l}=\sum_{i} E_{i} \times p_{i}
$$

Among which $E_{c l}$ represents the electrical consumption in the total process of material manufacturing, $E_{i}$ represents the power consumption of its material, $p_{i}$ represents the specific gravity of the material. Here mainly take the positive and negative materials and copper foil and aluminum foil

In the assembly process, because the process is complex and it is impossible to determine the power consumption of a single process in detail, the overall measurement is used. Use the total annual power consumption of the assembly plant, divided by the total weight of the product, to obtain the power consumption per unit mass of lithium battery assembly, as follows:

$$
E_{\mathrm{zz}}=\frac{E_{\mathrm{a} l l}}{M}
$$

Among which, $E_{z z}$ represents battery assembly power consumption per unit mass, $E_{\text {all }}$ is total annual electricity consumption, $M$ is total product quality.

Finally, convert the electricity consumption to standard coal consumption for power generation coal, the formula is as follows:

$$
T C E_{l}=\rho \times\left(E_{c l}+E_{\mathrm{zz}}\right)
$$

In the formula, $T C E_{l}$ represents ton of standard coal equivalent of lithium batteries, $\rho$ represents conversion factor.

According to the data provided in the document[17], about 23.71 tons of carbon dioxide emitted from the production of one ton battery.

The amount of carbon emitted during the driving process of electric vehicles depends on the electricity consumption and the impact of primary energy on the environment. In the coordinated dispatch of electric vehicles and wind power, primary energy is mainly thermal power and wind power. In the following, the actual situation will be analyzed and calculated. In order to combine the carbon emissions in the production of lithium batteries with the carbon emissions in the following driving process, it is calculated to the mileage. Assume that the electric vehicle has a full life cycle of $150,000 \mathrm{~km}$, Battery cycles up to 10 years, only one battery is required for the life cycle of an electric vehicle. E150V electric vehicle battery weight is about $300 \mathrm{~kg}$. This article use it to calculate the amount of carbon dioxide emitted by electric vehicles per degree of electric discharge. The formula is as follows:

$$
I_{e v}=\frac{I_{\text {sum }}}{S_{\text {sum }} \cdot(W / 100) \cdot \eta_{c}}
$$

Among which, $I_{\text {sum }}$ represents Total carbon emissions, $S_{\text {sum }}$ represents total mileage, $W$ is $100 \mathrm{~km}$ power consumption, $\eta_{c}$ is charging efficiency. The value obtained is approximately $351.26 \mathrm{t} / \mathrm{GWh}$. 


\section{Electric Vehicle ChARgING LOAD MODELING AND WIND POWER OUTPUT MODELING}

First of all, modeling the charging load of electric vehicles. Assume that the charging start time, initial SOC, and target SOC are independent of each other.

According to data statistics, the electric car starts charging time is presented as approximately the normal distribution[18]. Its probability density function is as follows:

$$
f_{t}= \begin{cases}\frac{1}{\sigma_{1} \sqrt{2 \pi}} \exp \left[-\frac{\left(t-\mu_{1}\right)^{2}}{2 \sigma_{1}^{2}}\right] \quad\left(\mu_{1}-12\right)<t \leq 24 \\ \frac{1}{\sigma_{2} \sqrt{2 \pi}} \exp \left[-\frac{\left(t+24-\mu_{2}\right)^{2}}{2 \sigma_{2}^{2}}\right] \quad 0<t \leq\left(\mu_{2}-12\right)\end{cases}
$$

Among which, $\sigma_{1}=5.4, \sigma_{2}=9.6, \mu_{1}=18.6, \mu_{2}=13$.

The initial SOC of the on-board battery and the target SOC at the end of charging are the same as the initial charging time when the electric vehicle arrives at the charging station to start charging, they both have a degree of randomness. This article uses probabilistic models to describe them, the formula is as follows:

$$
\begin{aligned}
& f\left(S_{0}\right) \frac{1}{\sigma_{0} \sqrt{2 \pi}} \exp \left[-\frac{\left(s-\mu_{0}\right)^{2}}{2 \sigma_{0}^{2}}\right] \\
& f\left(S_{t}\right) \frac{1}{\sigma_{t} \sqrt{2 \pi}} \exp \left[-\frac{\left(s-\mu_{t}\right)^{2}}{2 \sigma_{t}^{2}}\right]
\end{aligned}
$$

Among them, $S_{0}$ is Initial SOC, which is usually between 0.1 and 0.6. $S_{t}$ is target SOC, which is usually between 0.5 and 1.0. $\mu_{0}=0.35, \sigma_{0}=0.3, \mu_{t}=0.8, \sigma_{t}=0.3$.

This article assumes that electric vehicles are charged at a constant power, taking the charging power at $100 \mathrm{~kW}$. Therefore, based on the charging power and the initial SOC and the target SOC, the charging duration can be calculated. Then, according to the above model, the charging amount of the electric vehicle in each period is simulated, and then the charging load in each period is obtained.

Second, simulate the wind power output. Here we use the two-parameter Weibull wind speed model. The formula is as follows:

$$
f_{V}(v)=\frac{k}{c}\left(\frac{v}{c}\right)^{k-1} \exp \left[-\left(\frac{v}{c}\right)^{k}\right]
$$

In the formula above, $\mathrm{k}$ and $\mathrm{c}$ are the shape parameters and scale parameters of Weibull distribution.
Combining the Weibull wind speed model, assuming constant air density and linearized active power output curve, the wind power output segment function is obtained:

$$
p^{w}= \begin{cases}0 & v<v_{\text {in }} \text { 或 } v>v_{\text {out }} \\ p_{r}^{w} \frac{v-v_{\text {in }}}{v_{r}-v_{\text {in }}} & v_{\text {in }} \leq v<v_{r} \\ p_{r}^{w} & v_{r} \leq v<\leq v_{\text {out }}\end{cases}
$$

Among them, $V_{\text {in }}, V_{\text {out }}$ and $V_{r}$ correspond to the cut-in wind speed, cut-out wind speed and rated wind speed of the wind turbine. $P_{r}{ }^{w}$ is Wind turbine rated active output. When the wind speed is more than the $V_{i n}$, Wind turbine can start and run normally. When the wind speed is greater than $V_{r}$ and less than $V_{\text {out }}$, the wind turbine active power maintains at the rated value. When the wind speed is less than $V_{\text {in }}$ or greater than $V_{\text {out }}$, wind turbine stop working.

\section{ELECTRIC VEHICLE-WIND POWER COOPERATIVE SCHEDULING MODELING}

\section{A. Objective Function}

This article mainly examines the carbon emission reduction benefits of electric vehicles, so the minimum carbon emission is an objective function. Here, we mainly consider the carbon emissions of thermal power itself, and the carbon emissions corresponding to the charging after the electric vehicle's full life cycle accounting, as follows:

$$
\min E_{h} \sum_{t=1}^{n} P_{h, t}+I_{e v} \sum_{t=1}^{n} P_{e v, t}
$$

Among them, $E_{h}$ denotes the carbon emission factor of thermal power, and $P_{h, t}$ denotes the thermal power output of tth period, $P_{e v, t}$ is the charging power of the electric vehicle during the tth period. Secondly, the system cost is considered to be the lowest. The system cost is divided into two parts. One is the thermal power unit operating cost, which is mainly composed of the power generation costs, and the other is the carbon transaction cost. The baseline method is used to allocate carbon emission quotas according to the output. The carbon emissions portion of the quota needs to pay an additional fee. On the contrary, the excess portion can be used to obtain corresponding benefits[16]. Therefore the objective function is as follows: 
Among which, $C_{f}^{\text {gas }}$ is the thermal power unit operating cost at $\mathrm{t}$ and $C_{t}{ }^{c}$ is the carbon transaction cost at $\mathrm{t}$.

Thermal power plant operating costs are expressed as:

$$
C_{t}^{\text {gas }}=\sum_{i=1}^{N}\left(\mathrm{a}_{\mathrm{i}}+\mathrm{b}_{\mathrm{i}} \mathrm{P}_{\mathrm{i}, \mathrm{t}}+\mathrm{c}_{\mathrm{i}} \mathrm{P}_{\mathrm{i}, \mathrm{t}}\right)
$$

Where $a_{i}, b_{i}$ and $c_{i}$ are the power generation cost coefficients for the $i$-th generator.

Carbon transaction costs are as follows:

$$
\begin{gathered}
C_{t}^{c}=K\left(P_{c, t}-M_{t}\right) \\
M_{t}=\sum_{i=1}^{N} \varepsilon \mathrm{P}_{\mathrm{i}, \mathrm{t}}
\end{gathered}
$$

Among them, $K$ is the carbon trading price, $P_{c, t}$ is the actual carbon emission of the system at time t, and $M_{t}$ is the carbon emission quota at time t. $\varepsilon$ is the quota factor.

Finally, one of the purposes of coordinated dispatching of wind power and electric vehicles is to cut peaks and fill valleys to ease system peaking pressure. Therefore, set an $\mathrm{M}$ time period as a time window to minimize the equivalent variance of each time window(1). The formula is as follows:

$$
\begin{gathered}
\min \sum_{i=1}^{T-M} \sum_{t=i}^{i+M-1}\left(P_{l, t}-P_{w, t}+P_{e v, t}-P_{a v, i}\right)^{2} \\
P_{a v, i}=\frac{1}{M} \sum_{t=i}^{i+M-1}\left(P_{l, t}-P_{w, t}+P_{e v, t}\right)
\end{gathered}
$$

Where $P_{w, t}$ is the wind power output at time $\mathrm{t}$ and $P_{l, t}$ is the normal load at time t. $P_{a v, i}$ is the average of the equivalence load of the i-th time window.

\section{B. Constraints}

\section{1) System constraints:}

The system must meet the load and output balance as follows:

$$
\sum_{i=1}^{N} \mathrm{P}_{\mathrm{i}, \mathrm{t}}+P_{w, t}=P_{l, t}+P_{e v, t}
$$

2) EV charging constraints:

The charging load of the electric vehicle in each period shall be less than the EV charging load that can be dispatched during this period. The constraints are as follows:

$$
0 \leq P_{e v, t} \leq P_{c h, t}
$$

Among which, $P_{c h, t}$ is the upper limit of the dispatchable charging power of an electric vehicle in t period.

In addition, in order to ensure the battery service life and prevent the deep charge and discharge, it is necessary to ensure that the power has a certain balance and shall be less than the upper limit of the battery capacity. The constraints are as follows:

$$
S_{\min } \leq S_{t} \leq S_{\max }
$$

In which, $S_{\min }$ and $S_{\max }$ are the upper and lower limits of the battery storage capacity. $S_{t}$ is the remaining battery power at time $\mathrm{t}$.

Finally, the total charging demand of electric vehicles under collaborative scheduling should be greater than or equal to the charging demand of electric vehicles when they are freecharging, and the constraints are as follows:

$$
\sum_{t=1}^{T} P_{e v, t} \geq P_{f}
$$

Among them, $P_{f}$ is the sum of the charge demand when the electric car is free to charge.

3) Thermal power plant output constraints:

a) Output constraints: The output of each thermal power unit should be between its upper and lower limits, as follows:

$$
P_{i}^{\min } \leq \mathrm{P}_{\mathrm{i}, \mathrm{t}} \leq P_{i}^{\max }
$$

Among them, $P_{i}^{\max }$ and $P_{i}^{\min }$ are the upper and lower limits of the output of the $\mathrm{i}$-th thermal power unit.

b) Climbing constraint: The rate of increase or decrease in power plant output has its limit value, as follows:

$$
-R_{i}^{D} \Delta t \leq \mathrm{P}_{\mathrm{i}, \mathrm{t}}-\mathrm{P}_{\mathrm{i}, \mathrm{t}-1} \leq R_{i}^{U} \Delta t
$$

Among which, $R_{i}{ }^{D}$ and $R_{i}^{U}$ are the maximum landslide and climbing power in unit time. 
4) Wind power output constraints:

$$
0 \leq P_{w, t} \leq P_{w, t}^{\max }
$$

Among them, $P_{w, t}^{\max }$ is the maximum value of wind power output at time $\mathrm{t}$.

\section{Model Solving}

This paper mainly uses multi-objective particle swarm optimization algorithm. Particle Swarm Optimization (PSO) simulates the behavior of birds in flight for foraging. The collective cooperation among birds enables the group to achieve its goal. The multi-objective particle swarm algorithm is based on the improvement of the particle swarm algorithm. Non-dominated relationship ranking, particle crowding distance calculation, and tournament selection are added to the algorithm to finally obtain the pareto frontier of particles[19].

The basic flow of the multi-objective particle swarm algorithm is as follows:

1) Initialize the population randomly and set the inertia weight.

2) Solve the particle's objective function value.

3) Non-dominated sorting of particles according to fitness.

4) Calculate the crowded distance of each particle.

5) According to the frontier level and the crowded distance of the particles, the tournament selection method is used to select the individual optimal and global optimum of the population.

6) Update the particles according to the following formula:

$$
\begin{gathered}
V_{i, j}(t+1)=\omega V_{i, j}(t)+c_{1} \times \operatorname{rand}() \times\left[\text { pbest }_{i, j}-x_{i, j}(t)\right]+ \\
c_{2} \times \operatorname{rand}() \times\left[\text { gbest }_{i, j}-x_{i, j}(t)\right] \\
x_{i, j}(t+1)=x_{i, j}(t)+V_{i, j}(t+1)
\end{gathered}
$$

$V i$ is the velocity of the particle, pbest and gbest are the best and global best positions of the particle, rand represents the random number between 0 and 1, c1, c2 are the learning factors, and $\omega$ represents the inertia weight.

7) Repeat steps 2-6 until iteration conditions are met.

The best particles are picked in the pareto set and solved using fuzzy theory. This paper seeks to minimize carbon emissions and minimize costs, using a partial small fuzzy membership functions[5].

$$
\omega_{i}= \begin{cases}1 & f_{i} \leq f_{i}^{\min } \\ \frac{f_{i}^{\max }-f_{i}}{f_{i}^{\max }-f_{i}^{\min }} & f_{i}^{\max }>f_{i}>f_{i}^{\text {min }} \\ 0 & f_{i} \geq f_{i}^{\max }\end{cases}
$$

$$
\omega=\frac{1}{m} \sum_{i=1}^{m} \omega_{i}
$$

Among them, when $\omega_{i}$ equals to 0 , it represents the complete dissatisfaction, while when $\omega_{i}$ equals to 1 , it represents the complete satisfaction of the target $\mathrm{i}$ function value. $f_{i}$ is the objective function value. Equation (27) is used to obtain the normalized degree of satisfaction in the pareto solution set, and then the pareto solution with the largest $\omega$ value is selected as the optimal solution.

\section{CASE ANALYSIS}

This paper considers the installed capacity of wind turbine $10 \mathrm{GW}$, load data is refer to the document[4], and the reference value of the thermal power plant composition is come from document[20]. Then converts coal prices, the carbon emission allowance coefficient is $0.8112 \mathrm{~kg} / \mathrm{kWh}$, and the carbon price is 0.25 yuan $/ \mathrm{kg}$. The inspection period is 24 hours. According to the second quarter wind power output probability model, the 24 hours wind power is as follows (See Figure I):

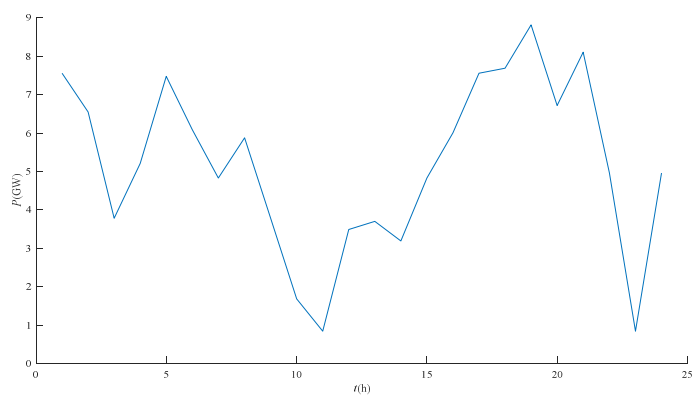

FIGURE I. 24 HOURS WIND POWER OUTPUT CURVE

Assume that the power grid occurs the situation of wind curtailment when the load variance is too large. According to the calculation results of the free charging and co-scheduled charging model of the electric vehicle, a reasonable free charging curve is obtained in Figure II, and the co-charging curve is shown in Figure III. 


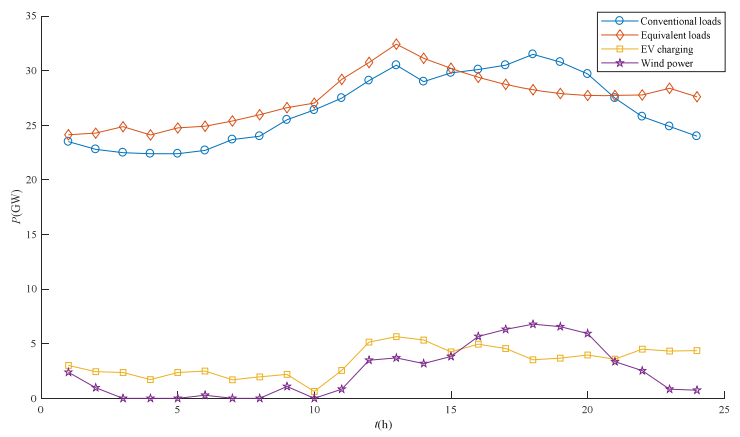

FIGURE II. ELECTRIC CAR FREE CHARGING CURVE

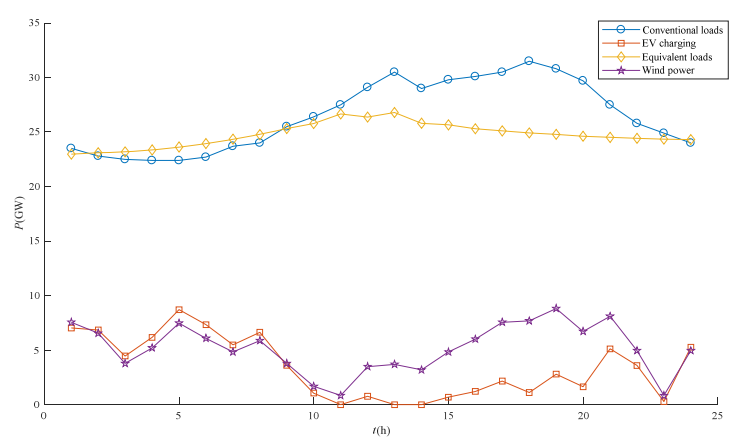

FIGURE III. ELECTRIC VEHICLE COORDINATED DISPATCH CHARGING CURVE

It can be seen that, in the case of meeting certain charging requirements, after coordinated scheduling of electric vehicle charging, the peak-to-valley difference can be effectively reduced, the load curve can be balanced, and the utilization rate of wind power can also be improved.

Under the two charging modes, the system's equivalent load variance, unit power carbon emissions, and power generation costs, including carbon transaction costs, will be compared in Table I as follow:

\section{TABLE I. COMPARISON OF FREE CHARGING AND COOPERATIVE} CHARGING DATA

\begin{tabular}{|c|c|c|c|c|}
\hline $\begin{array}{c}\text { Charging } \\
\text { scheme }\end{array}$ & $\begin{array}{c}\text { Equivale } \\
\text { nt load } \\
\text { variance } \\
\left(\mathbf{G W}^{2}\right)\end{array}$ & $\begin{array}{c}\text { Electricit } \\
\mathbf{y} \text { cost } \\
\text { (million) }\end{array}$ & $\begin{array}{c}\text { Unit power } \\
\text { carbon } \\
\text { emissions } \\
\text { (kg/kwh) }\end{array}$ & $\begin{array}{c}\text { Wind } \\
\text { utilization }\end{array}$ \\
\hline $\begin{array}{c}\text { Free } \\
\text { charging }\end{array}$ & 30.42 & 260.603 & 1.160 & $59.6 \%$ \\
\hline $\begin{array}{c}\text { Cooperative } \\
\text { charging }\end{array}$ & 4.79 & 228.335 & 1.104 & $100 \%$ \\
\hline
\end{tabular}

It can be seen that under coordinated charging, the carbon emissions of the system are greatly reduced, and due to the addition of the carbon trading mechanism, the power generation cost of the system has also been greatly reduced. The EV150 electric vehicle can travel about $150 \mathrm{~km}$ using 25 $\mathrm{kWh}$. According to the carbon emissions of the system unit's electricity, the carbon emissions of the electric vehicle's mileage are calculated to be $0.184 \mathrm{~kg} / \mathrm{km}$, and the unit carbon mileage of a small pure fuel vehicle is $0.192 \mathrm{~kg}$. $/ \mathrm{km}$, it can be seen that electric vehicles do have advantages in energy conservation and emission reduction.

In this scenario, change the ratio of the installed capacity of the wind turbine to the capacity of the thermal motor assembly, and the carbon emissions per unit mileage of the electric vehicle are calculated as shown in Table II:

TABLE II. CARBON EMISSION PER UNIT MILEAGE FOR DIFFERENT WIND POWER INSTALLATION CAPACITY RATIOS

\begin{tabular}{|c|c|}
\hline $\begin{array}{c}\text { Wind power and thermal } \\
\text { power installed capacity ratio }\end{array}$ & $\begin{array}{c}\text { Carbon emissions of electric } \\
\text { vehicle per mileage (kg) }\end{array}$ \\
\hline 0 & 0.21 \\
\hline $1 / 24$ & 0.204 \\
\hline $1 / 12$ & 0.197 \\
\hline $1 / 8$ & 0.191 \\
\hline $1 / 6$ & 0.184 \\
\hline $5 / 24$ & 0.177 \\
\hline
\end{tabular}

It can be seen that in a pure thermal power system, the carbon emissions of electric vehicles are even higher than that of traditional fuel vehicles. Under the dispatch strategy, the greater the capacity of wind power grid connection, the more able it is to reflect the Superiority of the energy saving and emission reduction of electric vehicles.

\section{CONCLUSION}

This paper establishes a coordinated dispatch model for wind power and electric vehicle charging in a low-carbon economy, and simulates the model. Based on the calculation of the carbon emissions of the whole life cycle of electric vehicles, the carbon emissions of electric vehicles under free charging and coordinated dispatch and the carbon emissions of fuel vehicles are compared. It can be seen that coordinated scheduling is used to absorb wind power and smooth the load curve, and coordinated scheduling brings huge advantages in environmental and economic benefits. However, under certain circumstances, the carbon emissions per unit mileage of electric vehicles is even higher than that of fuel vehicles. Therefore, it is of great significance to ensure that the utilization rate of clean energy is really reducing the emissions of electric vehicles.

\section{ACKNOWLEDGMENT}

Thanks for the support of the technology project of SGCC (Research and demonstration of new generation charging and discharging technology for electric vehicle based on energy Internet, 5206001601Y2).

\section{REFERENCES}

[1] YU Dayang, SONG Shuguang, ZHANG Bo, HAN Xueshan. Synergistic dispatch of PEVs charging and wind power in Chinese regional power grids[J], Automation of Electric Power Systems, 2011, 35(14):25-29.

[2] Ivan Pavić, Tomislav Capuder, Ninoslav Holjevac*. Role and impact of coordinated EV charging on flexibility in low carbon power systems[C]. Electric Vehicle Conference, 2015:1-8.

[3] D.Yamashita, T. Niimura. Optimal strategy to support the development of charging infrastructure for electric vehicles towards low carbon emissions[C]. Power \& Energy Society General Meeting, 2012:1-7. 
[4] YU Dayang, Huang Haili, Lei Ming, Li Xin, et al. CO2 reduction benefit by coordinated dispatch of electric vehicle charging and wind power[J]. Automation of Electric Power Systems, 2012, 36(10):14-18.

[5] HOU Jianchao, HU Qunfeng, TAN Zhongfu. Multi-objective optimization model of collaborative WP-EV dispatch considering demand response[J]. Electric Power Automation Equipment, 2016, 36(7): 22-27.

[6] SHI Quansheng, DI Chao, SUN Jiajia, ZHANG Shenfu, LI Shidong. An environmental and economic model of grid dispatching coordinated with wind powers and plug-in electric vehicles[J]. Journal of Shanghai University of Electric Power, 2017, 33(2):113-118.

[7] ZHANG Jing, TANG Yi, CHEN Cheng, XIANG Li. Coordinated charging strategy for electric vehicles considering time-of-use price and peak-Valley difference dynamic constraints[J]. Power System and Clean Energy, 2014, 30(5):79-84.

[8] WEI Dajun, ZHANG Chenghui, SUN Bo. A time-of-use price based multi-objective optimal dispatching for charging and discharging of electric vechicles[J]. Power System Technology, 2014, 38(11):29722977.

[9] GE Shaoyun, WANG Long, LIU Hong, et al. An optimization model of peak-valley price time-interval considering vehicles-to-grid[J]. Power System Technology, 2013, 37(8):2316-2321.

[10] SUN Bo, SUN Jiajia, DONG Hao. Unit dispatch optimization model of electrical vehicle to accommodate the wind power based on time-of-use charging price[J]. Renewable Energy Resources, 2017.35(1):110-118.

[11] TONG Jingjing, WEN Junqiang, WANG Dan, et al. Multi-objective optimization charging strategy for plug-in electric vehicles based on time-of-use price $[\mathrm{J}]$. Power System Protection and Control, 2016,44(1):17-23.

[12] LIU Zhi-zhen, YANG Yong, QU Dong-ming, et al. Coordinated charging strategy for electric vehicle aggregator based on time-of-use price[J]. Electric Machines and Control, 2017, 21(10):1-7.

[13] XU Zhiwei, HU Zechun, SONG Yonghua, et al. Coordinated charging strategy for PEV charging stations based on dynamic time-of-use tariffs[J], Proceedings of the CSEE, 2014, 32(22):3638-3646.

[14] S Skarvelis-Kazakos, P Papadopoulos, I Grau. Carbon optimized virtual power plant with electric vehicles[C], Universities Power Engineering Conference, 2010:1-6.

[15] HUANG Guihong, LEI Xia, YANG Yi, et al. Two-layer smart chargedischarge strategies for electric vehicles considering wind generation and users' satisfaction[J]. Transactions of China Electrotechnical Society, 2015, 30(5):85-97.

[16] LIU Zuoyu, QI Feng, WEN Fushuan, ZHANG Xizhu, WANG Lei. Economic and environmental dispatching in electric vehicles embedded virtual power plants with participation in carbon trading[J]. Electric Power Construction, 2017, 38(9):45-52.

[17] PAN Xiangyun. Life cycle greenhouse gas emission assessments of battery electric vehicles [D]. Shanghai:Tongji University, 2014.

[18] XU Shangyu. Capacity ratio method of electric vehicle charging station with scenery storage[D].Chengdu: University of Electronic Science and Technology of China, 2016.

[19] PEI Shengyu, ZHOU Yongquan. A multi-objective particle swarm algorithm based on the pareto optimization solution set $[\mathrm{J}]$. Computer Engineering and Science, 2010, 32(11):85-88

[20] DONG Anyou. Multi-approach and optimization model for accommodating China's curtailed wind power[D]. Beijing: North China Electric Power University. 